Revista Científica General José María Córdova

(Revista Colombiana de Estudios Militares y Estratégicos)

Bogotá D.C., Colombia

ISSN 1900-6586 (impreso), 2500-7645 (en línea)

Web oficial: https://www.revistacientificaesmic.com

\title{
La estrategia de la ONU y la Unión Europea contra las redes transatlánticas del narcotráfico
}

\author{
Sara Núńez de Prado Clavell \\ https://orcid.org/0000-0002-4809-5892 \\ sara.clavell@urjc.es \\ Universidad Rey Juan Carlos, Madrid, España \\ Javier Rodríguez Abengózar \\ https://orcid.org/0000-0003-0079-0551 \\ javier.abengozar@urjc.es \\ Universidad Rey Juan Carlos, Madrid, España
}

Citación APA: Núnez de Prado Clavell, S., \& Rodríguez Abengózar, J. (2022). La estrategia de la ONU y la Unión Europea contra las redes transatlánticas del narcotráfico. Revista Científica General José María Córdova, 20(37), 71-88.

https://dx.doi.org/10.21830/19006586.864

Publicado en línea: $1 .^{\circ}$ de enero de 2022

Los artículos publicados por la Revista Cientifica General José María Córdova son de acceso abierto bajo una licencia Creative Commons: Atribución - No Comercial - Sin Derivados.
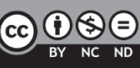

Para enviar un artículo:

https:/www.revistacientificaesmic.com/index.php/esmic/about/submissions
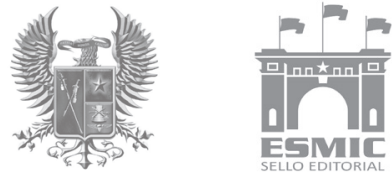

Miles Doctus 


\title{
La estrategia de la ONU y la Unión Europea contra las redes transatlánticas del narcotráfico
}

\section{UN and EU strategy against transatlantic drug trafficking networks}

\author{
Sara Núñez de Prado Clavell y Javier Rodríguez Abengózar \\ Universidad Rey Juan Carlos, Madrid, España
}

RESUMEN. Con una larga historia, el problema del narcotráfico ha ido incrementándose en las últimas décadas hasta alcanzar dimensiones globales. Este artículo estudia la evolución y el estado actual de la estrategia normativa de la Organización de las Naciones Unidas y la Unión Europea contra este problema, que actualmente se encuentra inserto en las redes del crimen organizado transnacional, en especial las redes transatlánticas. Se concluye que, a pesar de todo el ingente esfuerzo en esta lucha, lejos de combatirlo eficazmente, los resultados son muy pobres, tanto en los contextos nacionales más afectados como a nivel global.

Palabras ClaVE: crimen organizado; Naciones Unidas; narcotráfico; redes transatlánticas; Unión Europea

ABSTRACT. With a long history, drug trafficking has been a growing problem in recent decades that has reached global dimensions. This article studies the evolution and current status of the normative strategy of the United Nations and the European Union against this problem, currently embedded in transnational organized crime networks, especially transatlantic networks. It concludes that, despite all the enormous effort in this fight, far from combating it effectively, the results are abysmal, both in the most affected national contexts and at the global level.

KEYwORDS: drug trafficking; European Union; organized crime; transatlantic networks; United Nations

Sección: Seguridad y Defensa • Artículo de investigación científica y tecnológica

Recibido: 20 de agosto de 2021 • Aceptado: 24 de noviembre de 2021

ConTaCto: Sara Núnez de Prado Clavell 囚 sara.clavell@urjc.es 


\section{Introducción}

El tráfico internacional de drogas no es un fenómeno reciente. A principios del siglo $\mathrm{XX}$, se realizaron las primeras convenciones internacionales para el control del tráfico de opiáceos. La primera fue la Comisión Nacional del Opio, convocada en 1909 por Estados Unidos, y a la que asistieron nueve países. En 1912, se celebró en La Haya la Convención sobre el Opio, a la que acudieron doce países, incluido Estados Unidos. A partir de ese momento, las negociaciones entre los Estados para el control y la prohibición de las drogas no destinadas al consumo médico se comenzaron a hacer bajo el amparo de la Sociedad de Naciones, en cuyo seno se creó el Comité Asesor sobre Tráfico de Opio y otras Drogas Peligrosas. Después llegó la Convención del Opio, celebrada en Ginebra en 1925. Una vez desaparecida la Sociedad de Naciones, la lucha internacional contra las drogas la asumió la Organización de las Naciones Unidas (ONU), que a lo largo del tiempo ha tenido un papel activo — como se verá en este artículo—, aunque no brillante, en el control de los estupefacientes.

Hablar hoy de las redes del narcotráfico, especialmente de la cocaína ${ }^{1}$, es hablar de criminalidad organizada. La Convención de las Naciones Unidas contra la Delincuencia Organizada Transnacional, en su artículo 2a, define como grupo delictivo organizado aquel formado por

[...] tres o más personas que exista durante cierto tiempo y que actúe concertadamente con el propósito de cometer uno o más delitos graves o delitos tipificados con arreglo a la presente Convención con miras a obtener, directa o indirectamente, un beneficio económico u otro beneficio de orden material. (Oficina de las Naciones Unidas contra la Droga y el Delito [UNODC], 2004a)

Esta delincuencia organizada, en particular la que tiene vocación internacional, abarca diversos crímenes, como el narcotráfico, la trata de personas, el tráfico de armas, objetos o animales, el ciberdelito, el blanqueo de capitales proveniente de dichos delitos y la corrupción que los acompaña. En todo caso, autores como Lampe (2001), Paoli (2002) y Allum y Gilmour (2012) consideran que las definiciones sobre crimen organizado suelen ser poco precisas o, incluso, contradictorias.

Este trabajo analiza la estrategia normativa de la ONU y de la Unión Europea, tanto en el control de las drogas en general como más específicamente en el de las redes

1 Existen diversos espacios de contrabando de la cocaína: las rutas que llevan la droga desde países sudamericanos como Colombia, Ecuador, Bolivia o Perú hacia Estados Unidos, pasando por México, Centroamérica o el Caribe. Y otras que parten de los mismos lugares, pero que a través de Brasil o el Caribe llegan ya directamente a Espańa y Países Bajos, o hacen escala en Nigeria (hoy uno de los puertos principales) o en Sudáfrica, desde donde se destinan a los países del Golfo. Por otra parte, Turquía está empezando a tener protagonismo en estas rutas de la coca (antes el producto "estrella" era la heroína) como un punto de distribución importante para el Golfo. La peculiaridad es que la mayoría de la droga que llega a Turquía lo hace por el Canal de Suez rodeando África. Sobre esta cuestión es de gran interés el reciente informe del Observatorio Colombiano de Crimen Organizado (Saldarkhan, 2020). 
de distribución, que cada día adquieren una dimensión más global. El artículo, dividido en dos grandes bloques, recurre a una metodología de corte analítico-cualitativa basada en el análisis de contenido. La primera parte analiza las principales convenciones internacionales emanadas de la ONU y las medidas adoptadas en ellas para luchar contra el problema de la droga, así como la actividad de sus agencias especializadas más importantes. La segunda parte se centra en la labor frente al mismo tema de la Unión Europea y sus cuerpos especializados, que, como se verá, no difiere de la línea seguida por la ONU en la mayoría de sus actuaciones. Además de las convenciones y documentos oficiales, ha sido fundamental para este trabajo la información de sitios web oficiales y de otras fuentes, como algunos informes emanados de diversas organizaciones no gubernamentales, muy útiles para recabar información sobre las redes del narcotráfico y sus actividades. También se ha tenido en cuenta la bibliografía, clásica y actual, sobre este tema. Finalmente, en las conclusiones, se analiza la efectividad de dichas acciones y las posibles vías de lucha hoy en día contra este problema global.

\section{La ONU en la lucha contra las dirogas}

El primer paso importante en el seno de la ONU se produjo en 1961 con la firma de la Convención Única sobre Estupefacientes (CU) para el control de este tipo de sustancias. Entre los Estados firmantes, esta convención abrogó y sustituyó los convenios internacionales aprobados con anterioridad sobre tales cuestiones. La CU pretendió desde sus comienzos alcanzar toda la cadena, desde el cultivo hasta el consumo, pasando por la producción y la distribución ${ }^{2}$. Esta convención se aprobó en una conferencia celebrada en virtud de la Resolución 689 J (XXVI) del Consejo Económico y Social, del 28 de julio de 1958. Posteriormente, en 1972, fue modificada al amparo de la Resolución 1577 (L) del Consejo Económico y Social. Como consecuencia de este documento y de la necesidad de control expresada allí, en 1968 se creó la Junta Internacional de Fiscalización de Estupefacientes (JIFE). En estos años lo que preocupaba sobre todo era el cultivo de la amapola y el cannabis; solo después surgiría la preocupación por la cocaína.

La JIFE nació de la fusión de dos organismos anteriores: el Comité Central Permanente de Estupefacientes (creado a partir de la Convención Internacional del Opio de 1925) y el Órgano de Fiscalización de Estupefacientes (fundado en 1931 por mandato de la Convención para Limitar la Fabricación y Reglamentar la Distribución de Estupefacientes). Ambos documentos se habían aprobado en el seno de la Sociedad Naciones, y la ONU lo que hizo fue seguir y profundizar el camino que con ellos se había

$2 \quad$ La lucha contra el narcotráfico ha pasado por distintas fases. En general, los controles se han ampliado a lo largo del tiempo, cubriendo cada vez un espectro mayor hasta llegar a abarcar la cadena completa. Asimismo, de una política prohibicionista y represiva se ha evolucionado, no sin dificultades, a otra más global que, además de castigar, busca alternativas sociales para que la producción y el tráfico de drogas no sean la única opción de sobrevivir para determinados grupos sociales. 
iniciado. Esta junta se encuentra formada por trece miembros, expertos de prestigio e independientes de los gobiernos de su nacionalidad, elegidos para un mandato de cinco años (reelegibles una vez) por el Consejo Económico y Social, propuestos a través de una lista presentada por la Organización Mundial de la Salud.

La JIFE trabaja mediante reuniones, visitas oficiales (misiones de país), cuestionarios, etc., con el fin de determinar la situación de la fiscalización de drogas en los Estados y el cumplimiento general de sus gobiernos de las disposiciones de los tratados de fiscalización internacional de drogas. A partir de estos trabajos, elabora un informe que evalúa lo realizado por el país y en el cual incluye recomendaciones y peticiones encaminadas a conseguir que el Estado en cuestión cumpla con lo acordado en los diferentes tratados. Posteriormente, se realiza una nueva evaluación para comprobar si el país ha ejecutado las recomendaciones y exigencias expuestas. En caso de incumplimiento, la JIFE adopta las medidas que considere convenientes en aras de que el Estado cumpla sus compromisos, con base en el artículo 14 de la CU, que faculta a la junta para "pedir al Gobierno interesado que adopte las medidas correctivas que las circunstancias aconsejen para la ejecución de las disposiciones de la presente Convención" (CU, 1981).

Estas medidas pueden aumentar su severidad en función de las posibles amenazas que perciba la JIFE derivadas del incumplimiento por parte del Estado. Estas acciones se realizan respetando el anonimato del Estado implicado hasta que la Junta no considere imprescindible revelarlo, por lo cual sus actuaciones no cuentan con la efectividad que podría otorgar la publicidad. En caso de querer hacer público el nombre del Estado, debe comunicarlo a la Comisión de Estupefacientes y al Consejo Económico y Social, como se hizo con Afganistán, único país actualmente inserto en este proceso.

Poco después de la creación de la JIFE, se aprobó el Convenio sobre Sustancias Psicotrópicas (ONU, 1971) en virtud de la Resolución 1474 (XLVIII) del Consejo Económico y Social. En sus documentos se listan las sustancias que están sujetas a fiscalización, incluyendo los estupefacientes y los productos que pueden utilizarse para su fabricación. Estas listas son sometidas a actualización cada vez que se considera necesario, según el artículo 3.2 de la CU, que determina el procedimiento: "el Secretario General comunicará la notificación y los datos que considere pertinentes a las Partes, a la Comisión y, cuando la notificación proceda de alguna de las Partes, a la Organización Mundial de la Salud". La fiscalización corresponde a la Comisión de Estupefacientes del Consejo Económico y Social y a la JIFE, como lo establece el artículo 5 (CU, 1981).

En cuanto al tráfico ilícito, el artículo 35 de la CU establece, entre otras cuestiones, la obligación de las Partes de asegurar "en el plano nacional una coordinación de la acción preventiva y represiva contra el tráfico ilícito; para ello podrán designar un servicio apropiado que se encargue de dicha coordinación". También se hace referencia a que los Estados deben ayudarse "mutuamente en la lucha contra el tráfico ilícito de estupefacientes" (CU, 1981, art. 35b) y cooperar entre sí y "con las organizaciones internacionales 
competentes de que sean miembros para mantener una lucha coordinada contra el tráfico ilícito" (art. 35c). Y en el artículo siguiente, se determina que, siempre de acuerdo con las constituciones internas de cada país,

[...] cada una de las Partes se obliga a adoptar las medidas necesarias para que el cultivo y la producción, fabricación, extracción, preparación, posesión, ofertas en general, ofertas de venta, distribución, compra, venta, despacho de cualquier concepto, corretaje, expedición, expedición en tránsito, transporte, importación y exportación de estupefacientes, no conformes a las disposiciones de esta Convención o cualesquiera otros actos que en opinión de la Parte puedan efectuarse en infracción de las disposiciones de la presente Convención, se consideren como delitos si se cometen intencionalmente y que los delitos graves sean castigados en forma adecuada, especialmente con penas de prisión u otras penas de privación de libertad. (UNODC, 2014)

En 1988 se celebró la Convención contra el Tráfico Ilícito de Estupefacientes y Sustancias Sicotrópicas, con la intención de afrontar el problema de las drogas desde una perspectiva global. Esa fue la primera vez que se abordó el problema del tráfico ilícito transnacional, lo que marcó un hito en la historia de la lucha internacional contra el tráfico de drogas. En el preámbulo del documento final, los Estados reconocían estar profundamente preocupados

[...] por la sostenida y creciente penetración del tráfico ilícito de estupefacientes y sustancias sicotrópicas en los diversos grupos sociales y, particularmente, por la utilización de nińos en muchas partes del mundo como mercado de consumo y como instrumentos para la producción, la distribución y el comercio ilícitos de estupefacientes y sustancias sicotrópicas, lo que entraña un peligro de gravedad incalculable. (UNODC, 1988)

También se reconoció allí la existencia de vínculos "entre el tráfico ilícito y otras actividades delictivas organizadas relacionadas con él, que socavan las economías lícitas y amenazan la estabilidad, la seguridad y la soberanía de los Estados". Asimismo, se definieron diversos mecanismos de control y de cooperación técnica para el seguimiento de las medidas acordadas, entre ellos la obligación de informar a la Comisión de Estupefacientes del Consejo Económico y Social sobre sustancias que los países consideren que deben incluirse en las listas porque se utilizan con frecuencia en la fabricación ilícita de estupefacientes o sustancias psicotrópicas (UNODC, 1988, art. 12), o la de mantener canales de comunicación entre los organismos y servicios competentes de cada país.

Posteriormente, en la reunión ordinaria de 1990, la Asamblea General de la ONU dedicó una sesión al problema cada vez mayor de las drogas. Como consecuencia, se aprobó el Programa Global de Acción y se decidió que el periodo 1991-2000 se consideraría la "Década de las Naciones Unidas contra el Uso Indebido de Drogas". Un año después, apareció el Programa de Naciones Unidas para la Fiscalización Internacional de Drogas 
(PNUFID) $)^{3}$. Y aunque en las reuniones posteriores de la Asamblea General hubo intentos de poner en marcha una política general en la lucha contra las drogas, los resultados no fueron espectaculares, primordialmente por dos razones.

Primero, debido a las diferencias existentes entre los países implicados y su muy desigual grado de desarrollo político, social y económico. Estas diferencias inciden fundamentalmente en los ámbitos de oferta y demanda de la droga; o, lo que es lo mismo, en las disparidades existentes entre los países productores y los consumidores ${ }^{4}$. Y segundo, porque empezó a proponerse, sobre todo por la Unión Europea, una forma de control y lucha diferente, que tiende no solo a la imposición de medidas encaminadas a la prohibición y el castigo, sino también al desarrollo de políticas de prevención y de tratamiento sanitario. Este enfoque supuso la apertura de un nuevo debate que, si bien a la larga se impondría, en esos primeros años ralentizó el avance en la lucha contra las drogas y el narcotráfico.

En esta década, además, se abrió una nueva controversia que aún no se ha cerrado, relativa al uso legal de ciertas drogas, ya sea con fines terapéuticos o como medida contra el tráfico ilícito de ciertas sustancias, como el cannabis. Sobre este punto, la JIFE ha mostrado oposición, objetando que el argumento de que con ello se reducen algunos tipos de daños es más falaz que cierto y no es aplicable a todos los países.

En 1997, se creó en Viena la UNODC, con veinte sedes subregionales y dos más de coordinación y control en Nueva York y Bruselas. Como expresa en su sitio web:

[...] la labor de la UNODC consiste en educar a las personas en todo el mundo sobre los peligros del uso indebido de drogas y fortalecer las intervenciones internacionales contra la producción y el tráfico de drogas ilícitas y la delincuencia relacionada con las drogas.

\section{También contribuye a}

[...] mejorar la prevención del delito y presta asistencia en la reforma de la justicia penal a fin de fortalecer el Estado de derecho, promover sistemas estables y viables de justicia penal y combatir las crecientes amenazas de la delincuencia organizada internacional y de la corrupción. (UNODC, s. f.)

En 1998, la Asamblea General de la ONU encomendó a la UNODC que publicase periódicamente información puntual, completa y objetiva sobre el tema de las drogas. A raíz de ello, años después, en 2004, la UNODC publicó el informe mundial sobre drogas, que, si bien no se posiciona a favor de la legalización o de otros elementos de debate, sí se muestra abierto a la necesidad de discusiones objetivas que puedan auspiciar políticas más efectivas y diferentes en la lucha contra las drogas. que el control de la demanda se ha considerado de ámbito nacional, por lo que son los países autónomamente quienes lo controlan y legislan. Este es un enfoque que comenzó a cambiar a finales de los años ochenta. 
Dichas diferencias se comenzaron a manifestar en la Sesión Especial de la Asamblea General de Naciones Unidas (UNGASS) sobre el problema mundial de las drogas de 1998. La pretensión de esta reunión y del entonces secretario general de la ONU, Kofi Annan, era lograr erradicar los cultivos ilegales de drogas en un periodo de diez años, pero no se consiguió alcanzar consensos que tuvieran resultados prácticos reales y notoriamente exitosos, ya que el límite político nacional de muchos países productores afectaba la efectividad de los acuerdos. Por ejemplo, en el prefacio del informe mundial sobre las drogas de 2004, escrito por Antonio Costa, entonces director ejecutivo de la UNODC, se reconoció que, aunque se habían hecho progresos, "el nivel de uso indebido de drogas sigue siendo inaceptable". Y añadía:

hay que abordar el problema de las drogas en el contexto más amplio de la seguridad humana y del desarrollo sostenible, [...] las respuestas al vínculo entre las drogas y el delito deben ser más integradas. Los delincuentes obtienen enormes sumas de dinero tanto de los cultivadores pobres como de los adictos pobres. [...] los programas de fiscalización de drogas deben acomodarse mejor a la dinámica de los mercados de drogas: un mejor entendimiento de las tendencias subyacentes, unos datos más sólidos, un incremento de la investigación y un enfoque científico más profundo del problema son elementos necesarios. (UNODC, 2004b)

En 2009 se firmó la Declaración Política y el Plan de Acción sobre Cooperación Internacional hacia un Sistema Integrado de Estrategia equilibrada para contrarrestar el problema mundial de la droga, que dio a los países un plazo de diez años para abordar este problema con tareas concretas. Lo que se pedía entonces a los signatarios era que emprendieran políticas encaminadas a reducir los cultivos de coca, amapola y cannabis, así como su consumo. También se requería que afrontaran los problemas sanitarios derivados del tráfico ilícito de drogas y del consumo, a la vez que se solicitaban medidas contra las drogas sintéticas, que desde los años ochenta hacia adelante venían incrementando su desarrollo, fabricación y consumo. Otro tema que los países también debieron abordar a partir de dicha declaración es el tráfico ilícito de los precursores. Y finalmente, tomar medidas contra el blanqueo y lavado de dinero proveniente del mercado de las drogas.

Todos estos mandatos, sin embargo, han resultado ser poco efectivos en la práctica, por lo que los países más afectados por el narcotráfico se han sentido vulnerables al enfrentar un problema cada vez más arraigado y globalizado. Según datos de 2012, las áreas de cultivo de coca y su consumo habían disminuido, sobre todo en Colombia. Igualmente, la media general de consumo de cocaína en América del Sur había pasado del 0,9 \% al 0,7\% en 2010. Pero el problema seguía siendo la delincuencia asociada al narcotráfico. Así, en contraste con la tendencia mundial de esa década, en la que las tasas mundiales de homicidios se estabilizaban o disminuían, en el caso de América Latina y el Caribe aumentaron de 19,9 en 2003 a 32,6 homicidios por cien mil habitantes en 2008 (Seelke et al., 2011). De esta forma, Bruce Bagley (2014) explica que, 
como una consecuencia no intencional de la Guerra contra las Drogas patrocinada por los EE. UU. en Colombia, el escenario de la participación del crimen organizado en el tráfico de cocaína se trasladó poco a poco hacia el norte, de Colombia a México.

Por ello, en 2012, los presidentes de tres países duramente castigados por el problema del narcotráfico: México, Colombia y Guatemala, solicitaron ayuda a la ONU ante la baja efectividad demostrada por las políticas de lucha contra el tráfico de drogas. Ello llevó a la convocatoria de una reunión en 2016, que se adelantó en tres años a la fecha en que se cumplía el decenio.

Para facilitar la participación de los sectores implicados en todos los países, la ONU abrió un sitio web denominado UNGASS, con el fin de que las organizaciones no gubernamentales tuvieran espacio para exponer sus ideas. De esta manera, a la vez que se propiciaba la participación mundial, se utilizaría la información aquí recogida como herramienta base de trabajo para la celebración de la conferencia entre el 19 y el 21 de abril de 2016, junto con los informes que los distintos países envían desde 2014 a la Comisión de Estupefacientes de la ONU en relación con su política sobre el control del narcotráfico y los resultados obtenidos. Con esta documentación, la comisión elaboró el documento que se presentaría en UNGASS. Asimismo, se solicitó al Alto Comisionado para los Derechos Humanos preparar un estudio sobre el impacto que el problema mundial de las drogas tiene en el desarrollo y el disfrute de los derechos humanos.

Dicha conferencia extraordinaria (la número 30 de las celebradas por la ONU) se estructuró en diversas mesas de trabajo que incluían cuestiones como las drogas y la salud; las drogas y la delincuencia; las drogas y los derechos humanos; los jóvenes, las mujeres, los niños y las comunidades; los nuevos retos, amenazas y realidades en el ámbito de la prevención; la lucha contra el problema mundial de las drogas y el desarrollo alternativo, y la cooperación regional, interregional e internacional para lograr una política de fiscalización de drogas equilibrada y orientada al desarrollo (UNODC, 2016). Estos temas demuestran que la tendencia de la lucha global contra los diferentes aspectos que rodean al narcotráfico iniciada a finales de la década de los ochenta, casi cuatro décadas después, ya ha tomado carta de naturaleza en los enfoques teóricos de la ONU como la forma más adecuada de luchar contra el narcotráfico y todos sus delitos conexos. Cuestión aparte es el éxito y los logros de esa forma de luchar contra este problema, a consecuencia del compromiso real, no aparente, de los Estados en su pugna por erradicar el problema multidimensional de la droga ${ }^{5}$.

\section{Las recientes actuaciones de la ONU en la lucha contra el narcotráfico}

La reunión n. ${ }^{\circ} 62$ de la Comisión de Estupefacientes se celebró en 2019 con una asistencia récord, ya que se contabilizaron más de 2400 participantes entre Estados, organiza-

5 Para un análisis crítico de esta conferencia, puede consultarse a Bewley-Taylor y Jelsma (2016). 
ciones gubernamentales, instituciones académicas, sociedad civil y sector privado. En esa reunión, los Estados se comprometieron a

salvaguardar nuestro futuro y garantizar que nadie afectado por el uso de drogas se quede atrás, a medida que aumentamos nuestros esfuerzos para cerrar las brechas en el tratamiento de las tendencias y desafíos que emergen constantemente por este problema global. (UNODC, 2019)

En el informe de 2020, se constata que alrededor de 269 millones de personas usaron drogas en 2018, lo que implica un aumento del $30 \%$ con respecto al 2009. A esto se añade que, como consecuencia de esa cifra de consumo, son más de 35 millones las personas que sufren trastornos diversos. El cannabis sigue siendo la sustancia más consumida (192 millones de personas), aunque son los derivados del opio los que más muertes han causado en la última década ( $71 \%$ más que en los diez años anteriores). Este informe también señala que el consumo de cannabis ha aumentado en aquellos lugares en los que se ha legalizado (UNODC, 2020).

En octubre de 2020 se aprobó en Viena el mecanismo de revisión de la implementación de la Convención de las Naciones Unidas contra la Delincuencia Organizada Transnacional (Resolución 9/1; ONU, 2020) para evaluar el nivel y la calidad de la implementación de la Convención por parte de los Estados signatarios. Esta revisión, que básicamente consiste en una autoevaluación inspeccionada por otros dos países, se realizará en fases diferentes. Primero, mediante un cuestionario que debe contestar cada país y que será evaluado por los países designados como examinadores, quienes harán sus observaciones. Y después, los expertos, a partir de esa documentación, elaborarán sus listas de recomendaciones (ONU, 2020).

En principio, el proceso debería estar culminado con el primer grupo de países en mayo de 2022, aunque se prevén retrasos motivados por la pandemia. Donde se encuentren deficiencias, la ONU contribuirá a desarrollar las capacidades necesarias, incluida la asistencia técnica. El mecanismo en sí mismo resulta débil, pues se desconoce el grado de transparencia que habrá en su desarrollo, así como el grado de participación de diversos actores no gubernamentales implicados en el proceso.

\section{La Unión Europea y el combate contra las redes transatlánticas delictivas}

La Unión Europea mantiene acuerdos marco con muy diversos países enfocados en múltiples aspectos temáticos, que incluyen las cuestiones de seguridad, tráficos ilícitos y similares. Este trabajo se centra en algunos de los programas transatlánticos contra el tráfico de drogas y sus delitos conexos.

Uno de los más importantes ha sido el denominado Ruta de la Cocaína, centrado en la lucha contra la delincuencia organizada transnacional para el tráfico de esta sustancia 
(existe otro programa paralelo para las rutas de la heroína). Este acuerdo surgió en 2009 con el propósito de, bajo el amparo de la Unión Europea y de acuerdo con sus socios, trabajar por la supresión de los flujos de bienes ilícitos facilitando la comunicación entre investigadores y fiscales. El foco de atención es América Latina, el Caribe y las rutas de la cocaína que salen de estos lugares hacia África y Europa. Cuenta con nueve proyectos que se desarrollan mediante el Instrumento en Pro de la Estabilidad y la Paz (IcSP), que abarca más de cuarenta países. Desde 2019, con base en la experiencia anterior, existe el Programa de los Flujos Ilícitos Globales (PFIG), financiado por la Comisión Europea y centrado más en la delincuencia organizada que en el tráfico de drogas. Tiene vigencia hasta 2025 y cuenta con ocho subprogramas, algunos provenientes de la etapa anterior (PFIG, s. f.):

1. La prevención de la entrada de drogas y otros productos ilícitos. Para esta actividad se han puesto en marcha los programas Aircop, Seacop y Prelac. De estos tres proyectos, Prelac finalizó en 2016 y se desarrolló en colaboración con la UNODC. Su ámbito de aplicación fue América Latina y el objetivo era controlar y desviar los precursores químicos necesarios para la producción de cocaína y otras drogas. Los otros dos, aún en ejecución, se centran en controlar el tráfico de drogas tanto en aeropuertos (Aircop) como en puertos (Seacop), así como fomentar el intercambio de información. Cubren las rutas transatlánticas de las drogas, por lo que abarcan países de África, América Latina y el Caribe. El Seacop, además, tiene un apartado dedicado a fortalecer los equipos de inteligencia marítima (MIU).

2. Facilitar el intercambio de información y la cooperación entre distintas agencias encargadas del cumplimiento de la ley y las autoridades judiciales. Los instrumentos en este caso son los programas Wapis y Ameripol-EU.

a. El ámbito de trabajo de Wapis era África occidental, concretamente Benín, Ghana, Mali y Níger. Se centraba en conseguir que las instituciones policiales de estos países digitalizasen su documentación para poder facilitar y potenciar el intercambio de información a nivel regional, nacional e internacional. Contaba con el apoyo de la Interpol y de la Comunidad Económica de Estados de África (Ecowas, por sus siglas en inglés, o Cedeao). El programa reveló la creciente importancia que estaba adquiriendo la zona costera de África occidental en las rutas transatlánticas del tráfico ilícito. En el marco del Acuerdo de la Ruta de la Cocaína, estuvo vigente entre 2012 y 2013, cuando se cumplió su primera fase; luego siguió funcionando con dinero procedente de la Reserva Federal de Estados Unidos y del Programa Indicativo Regional UE-África Occidental, e incluyó a Mauritania en una segunda fase que finalizó en 2016. En una tercera fase, iniciada en 2017 y con una duración de 55 meses, amplió su radio de acción a una parte importante del Sahel. 
b. En el caso de Ameripol-EU, el objetivo era fortalecer la cooperación entre las autoridades policiales, judiciales y fiscales en América Latina y el Caribe en la lucha contra las redes del crimen organizado transnacional. Participaron Barbados, Bolivia, Brasil, Colombia, Ecuador, Panamá, Perú, Trinidad y Tobago y Venezuela. Entre sus logros está la puesta en funcionamiento del Sistema de Información Policial (SIPA) de Ameripol y la Comunidad de Policía de América. Hoy en día, sigue funcionando en el marco de EL PAcCTO (Europe Latin America Programme of Assistance against Transnational Organised Crime), como soporte de Ameripol.

3. Luchar contra el lavado de dinero proveniente de las drogas y actividades ilícitas conexas. Para ello se crearon los programas AML-WA y Gafilat-EU. El primero, enfocado en África occidental (Cabo Verde, Ghana, Nigeria y Senegal), tenía el objetivo de combatir el lavado de dinero proveniente del tráfico de drogas y otros delitos conexos. Para ello se puso en marcha la Red de Recuperación de Activos de África Occidental (ARIN-WA). En cuanto al segundo, que finalizó en junio de 2017, tenía el mismo propósito, pero en el contexto de los diecisiete países miembros de Gafilat (Grupo de Acción Financiera de América Latina).

4. Programa Crimjust para la colaboración en las investigaciones criminales y la justicia. Este programa, que sigue vigente, se concibe como un complemento general a todos los anteriores, por lo que su ámbito de aplicación es el ámbito global de la Ruta de la Cocaína (América Latina, el Caribe y África Occidental). En su implementación colaboran la UNODC, la Interpol y Transparencia Internacional. Está concebido para coadyuvar en

la cooperación y el intercambio de información entre los organismos de justicia penal para lograr una acción eficaz en casos de delincuencia organizada transnacional y tráfico de drogas, así como ayudar a los países del proyecto a avanzar en su respuesta a la delincuencia organizada. (Participación Ciudadana, s. f.)

Para la supervisión, coordinación, coherencia y complementariedad entre los distintos subproyectos o cualquier otra iniciativa en el marco del programa Ruta de la Cocaína, se puso en funcionamiento el Proyecto de Supervisión y Apoyo del Programa Ruta de la Cocaína (CORMS). El encargado de ejecutarlo es el Royal United Services Institute (RUSI), conformado por un grupo de expertos internacionales que trabajan desde 1831 en el campo de la seguridad y la defensa internacional con sede en Londres.

En cuanto al Instrumento en Pro de la Estabilidad y la Paz (IcSP), sustituye a otras iniciativas similares dispersas y sobre todo al Instrumento de Estabilidad (IfS), con el fin de potenciar y mejorar la lucha contra el crimen organizado. Entró en vigor en 2014 con una vigencia inicial hasta el 2020. Ha sido la principal herramienta de la Unión Europea para ayudar y colaborar en las iniciativas de seguridad y las actividades de consolidación de 
la paz que han puesto en marcha los países firmantes. Para la gestión de este instrumento se aprobó el Reglamento (UE) 230/2014 del Parlamento Europeo y el Consejo de la Unión Europea (2014) en vigor hasta el 31 de diciembre de 2020, en el que se establecían tres líneas de acción diferentes. La tercera de estas líneas se refería a la colaboración para hacer frente a amenazas mundiales y transregionales y a amenazas incipientes. Así, en el artículo 1.4c, se especificaba, entre otras cosas, que el objetivo del reglamento es "hacer frente a amenazas específicas mundiales y transregionales a la paz y a la seguridad y la estabilidad internacionales". Y el artículo 5 se refiere a que la Unión prestará ayuda técnica y financiera cuando se presenten "amenazas para la ley y el orden público, la seguridad y protección de los ciudadanos, infraestructuras de importancia vital y la salud pública”, así como para poner en marcha medidas encaminadas a

[...] potenciar la capacidad de las autoridades policiales, judiciales y administrativas que participan en la lucha contra el terrorismo, contra la delincuencia organizada, incluida la ciberdelincuencia, y todas las formas de tráfico ilícito, y en el control eficaz del comercio y el tránsito ilegales. (Parlamento Europeo \& Consejo de la Unión Europea, 2014)

A esto añade:

[...] en relación con la ayuda relacionada con el problema de las drogas, se prestará la debida atención a la cooperación internacional para la promoción de las mejores prácticas en relación con la reducción de la demanda, la producción y los daños.

Hay que destacar que en el artículo 13 establecía una dotación financiera para el periodo 2014-2020 de 2338719000 euros (Parlamento Europeo \& Consejo de la Unión Europea, 2014).

Otra herramienta de lucha contra las drogas es la Acción de la Unión Europea contra las Drogas y el Crimen Organizado (EU-ACT), gestionada por la Fundación Internacional y para Iberoamérica de Administración y Políticas Públicas (FIAPP) para potenciar la cooperación y coordinación policial regional y transregional en la lucha contra la delincuencia organizada y las actividades de tráfico de drogas. Dicha herramienta está centrada en la ruta de la heroína. Los encargados de su ejecución son expertos del Ministerio de Interior de Espańa, de Carabinieri de Italia y personal de la National Crime Agency (NCA) del Reino Unido. Tiene un presupuesto aportado por la Comisión Europea de doce millones de euros. Sus principales áreas geográficas de trabajo son los países del Cáucaso Sur o Medialuna de Oro, por donde entra la heroína procedente de Irán y Pakistán que llega hasta Turquía. Ucrania y Moldavia. Estos países, junto con Bielorrusia —que no está en el programa - y los países de Asia Central, conforman algunos de los mercados más importantes de Europa, todos en el Viejo Continente. A ellos se añaden Tanzania, Kenia y Mozambique en África, ya que a través de ellos se alcanza la Unión Europea por los 
puertos del sur. Por su parte, Pakistán, Irán y Afganistán, en Asia, utilizan la ruta de los Balcanes para llegar a Europa a través de Turquía.

Esta acción se puso en marcha en 2017 con una vigencia inicial de cuatro años. Tiene tres vías de acción sustanciales:

1. Trabajar en establecer políticas nacionales de implementación de respuestas operativas que potencien los éxitos en la lucha contra las drogas (Napor). Los países receptores de este subprograma son Kirguistán, Georgia, Ucrania, Pakistán y Tanzania.

2. Puesta en funcionamiento del Servicio de Asistencia Técnica (TAF) para ayudar a obtener respuestas conjuntas en la lucha contra las drogas, especialmente la encaminada a la reducción de la oferta y la demanda de heroína, aunque también en otros aspectos que los países participantes consideren necesarios. Se incluyen todos los países inscritos, aunque se da prioridad a los que no participan en el subprograma anterior. Aquí se trabaja siguiendo los lineamientos establecidos por la Estrategia y el Plan de Acción sobre Drogas y la Agenda de Seguridad de la Unión Europea.

3. Apoyo a Iniciativas de Cooperación (COPI) de tipo transregional que puedan insertarse en los dos anteriores subprogramas.

Como recuerda José Antonio Maté, coordinador del proyecto EU-ACT en la zona de Asia Central:

[...] las organizaciones de tráfico de drogas están establecidas en diferentes países. En un país pueden estar proporcionando la materia, otros países de tránsito, otros países de destino [...]. Incluso otros países para el lavado de dinero. Por tanto, si esto no se aborda desde un punto de vista transnacional, es imposible. (FIAPP, 2019)

Hay que hacer referencia al ya citado proyecto de asistencia EL PAcCTO (20172022), que, con financiación de la Unión Europea (22 410000 euros cada cinco años), es puesto en funcionamiento por FIIAPP y Expertise France. Además, cuenta con dos socios europeos: el Instituto Italo-Latinoamericano (IILA) y el Instituto Camóes de Portugal. Su objetivo principal es la lucha contra el crimen transnacional organizado focalizado en América Latina (cubre dieciocho países). Se enfoca en fortalecer las instituciones encargadas de luchar contra este problema en cada país proporcionándoles asistencia técnica. Como puntos de atención están los sistemas penitenciarios y la cooperación y coordinación entre distintos regímenes judiciales, así como la formación y especialización de las fuerzas de seguridad en la lucha contra este tipo de crímenes. También es fundamental para este proyecto promover la cooperación transfronteriza de todos los países implicados, en colaboración estrecha con Ameripol. 
En cuanto al papel de la Agencia de la Unión Europea para la Cooperación Policial (Europol), es relevante referirse a los informes que publica desde 2013 sobre la Evaluación de Amenazas de Delitos Graves y Organizados (SOCTA, por sus siglas en inglés). Como especifica la propia organización, más allá de una evaluación estratégica, es "la piedra angular" de la Plataforma Multidisciplinaria Europea contra las Amenazas Criminales (Empact $)^{6}$. Este programa, si bien reconoce que el narcotráfico sigue siendo un "área tradicional" de los delitos internacionales, pone el acento en la aparición de otras amenazas muy relacionadas con la globalización. Debido a ello, en su informe del 2017, identificó como las mayores amenazas globales, no solo la producción, el tráfico y la distribución de drogas, sino también otras cuestiones relacionadas, como los ciberdelitos y el tráfico de seres humanos (específicamente de migrantes), como también lo relacionado con lavado de dinero y finanzas criminales, así como el comercio en línea de bienes y servicios ilícitos, y el fraude documental. Estos tres últimos casos se consideran amenazas transversales.

Para el tema del narcotráfico se mantiene la división entre producción y distribución, incluida la distribución a través del comercio online. En el apartado de la producción, se reconoce que la Unión Europea es un importante productor de drogas sintéticas, con un considerable tráfico tanto de precursores como de pre-precursores. Entre la producción y la distribución se incluye el tráfico de cocaína que llega a la Unión Europea tanto por los puertos como a través de mensajeros. Y en cuanto a la distribución, se pone el acento en el alto tráfico de distintas drogas que hay en la Unión Europea y la gran subida que se ha producido en el tráfico de cannabis (al igual que en su producción).

Las conclusiones del informe ponen de manifiesto que los mercados de drogas siguen siendo los más importantes dentro de las actividades ilícitas, y generan importantísimos beneficios. En lo que se refiere al minorista, se calcula que mueve al ańo en torno a 24 millones de euros. Asimismo, se refiere a la corrupción como un recurso fundamental para facilitar sus actividades, que incluyen no solo la compra de precursores o maquinaria necesaria para la producción, sino también el uso de documentos falsos para crear empresas e importar drogas junto con otros bienes legales. Añade el informe que más de un tercio de los grupos involucrados se dedica tanto a la producción como al tráfico o distribución de las drogas.

En cuanto al análisis de los grupos delincuenciales organizados, se trabajó sobre una población de 5000 grupos que cubre unas 180 nacionalidades diferentes. Estos grupos se

$6 \quad$ El origen de Empact está en la decisión de la Unión Europea en 2010 de crear ciclos políticos de cuatro años en la lucha contra el crimen organizado, con el fin de fomentar la continuidad y cooperación entre Estados miembros, instituciones, agencias europeas, terceros países y, eventualmente, el sector privado. En 2017, el Consejo aprobó un nuevo periodo que cierra en 2021, centrado en la lucha contra la delincuencia organizada, siendo el tráfico de drogas uno de los puntos fundamentales. Se establecían los siguientes focos de lucha: "interrumpir las actividades de los grupos de delincuencia organizada (OCG) involucrados en el tráfico mayorista de cannabis, cocaína y heroína hacia la UE; abordar las redes delictivas involucradas en el tráfico y distribución de múltiples tipos de drogas en los mercados europeos; reducir la producción de drogas sintéticas y nuevas sustancias psicoactivas (NSP) en la UE y desmantelar los OCG implicados en su producción, tráfico y distribución" (Europol, s. f.). 
organizan de forma jerárquica. El $76 \%$ de ellos cuenta con más de seis miembros, de los cuales el $60 \%$ son nacionales de la Unión Europea, aunque siete de cada diez grupos están conformados por al menos tres nacionalidades diferentes (Europol, 2017).

El informe más reciente, el SOCTA de 2021, insiste en el hecho de que tanto la producción como el tráfico de drogas se mantienen como el mayor negocio delictivo en la Unión Europea; el $40 \%$ de las redes delictivas aún están activas. Las redes que abastecen los distintos mercados de la droga son cada vez más sofisticadas y diversificadas, y controlan desde la distribución al por mayor hasta el mercado minorista. También menciona el cada vez mayor uso de la violencia en las actividades de estas redes, sobre todo en los que trafican con cocaína y cannabis. $Y$, finalmente, señala que uno de los problemas crecientes en la Unión Europea es la producción de drogas sintéticas. En resumen, existe una constante expansión, crecimiento y evolución de la delincuencia organizada en la Unión Europea, que abarca no solo el mercado de la droga, sino todas las actividades delictivas asociadas y convergentes, como el tráfico de personas o de armas, la ciberdelincuencia, entre otras (Europol, 2021).

\section{A modo de conclusión}

La lucha contra el narcotráfico, si bien nunca ha sido fácil a lo largo de la historia, en la actualidad resulta cada vez más complicada debido a las oportunidades que ofrecen las nuevas tecnologías y la globalización. Es más, hoy ya no puede hablarse de narcotráfico de manera aislada, sino que los países y las organizaciones internacionales se enfrentan a un problema de dimensiones globales inserto en el conjunto del crimen organizado. Las rutas que mueven la droga operan también con otros tipos de mercancía, como las armas o la trata de personas. Son redes transatlánticas, diversificadas, especializadas y conectadas entre sí, lo que dificulta en gran medida su control y sobre todo su exterminio.

En las últimas décadas, las organizaciones internacionales y los Estados han tomado conciencia de ello y también han diversificado sus herramientas de lucha, así como han evolucionado en cuanto al concepto de lo que deben combatir. De las acciones de control, ataque y castigo, se ha pasado a incluir la prevención y las actividades postsolución, en un intento de dar alternativas a aquellos que no veían más salida que trabajar y permanecer en el ámbito del narcotráfico. La comunidad internacional parece empezar a entender que el narcotráfico ya es un problema que afecta a otros ámbitos como el sanitario, el educativo, los derechos humanos, etc. Un problema global requiere de soluciones globales, no solo en su diseño, sino también en su aplicación.

Cierto es que la realidad está aún muy lejos de las soluciones efectivas, ya que, si bien sobre el papel las cuestiones están muy claras, su transposición a la práctica es harto difícil. Sin olvidar, además, que en varios aspectos la normatividad y los acuerdos internacionales deben dejar que los países, debido a la imposibilidad de invadir su soberanía y competencias, asuman la iniciativa legal y de acción interna. Como consecuencia, la 
disparidad sigue siendo muy grande, la lucha se mantiene desigual y los resultados son muy pobres.

Si bien la Comisión de Estupefacientes sigue siendo el organismo protagonista en la lucha contra las drogas en el seno de la ONU, sus resultados carecen de éxitos reales, ya que los acuerdos no suelen traspasar el terreno del ámbito documental. Cierto es que su objetivo principal es formular propuestas encaminadas a fortalecer la fiscalización internacional, pero lo que falla es precisamente su implementación. Esta comisión también dirige la actividad de la UNODC, que es amplia y constante, pero irregular en cuanto a sus resultados. Junto a ella, la JIFE es la encargada de controlar que los Estados cumplan los compromisos adquiridos, pero no cuenta con capacidad real para imponer sanciones ante incumplimientos.

En cuanto a la Unión Europea, ha sido pionera en adoptar el enfoque global en la lucha contra el narcotráfico y, en convergencia con la ONU, ha puesto en marcha herramientas propias que van más allá de las fronteras de la Unión para colaborar con diversos países azotados por el narcotráfico, ya sea como puntos de tránsito, productores o consumidores.

Así, la lucha es difícil y se proyecta larga. Las políticas generales deben tener un aterrizaje práctico y efectivo que aún no se ha encontrado, por lo que el debate seguirá abierto durante mucho más tiempo.

\section{Agradecimientos}

Los autores desean agradecer al equipo del proyecto de investigación "Europeísmo y redes transatlánticas en los siglos XX y XXI” (PGC2018-095884-B-C22), del Ministerio de Ciencia e Innovación del Gobierno de España, por su apoyo en la realización de este artículo.

\section{Declaración de divulgación}

Los autores declaran que no existe ningún potencial conflicto de interés relacionado con el artículo. La autora forma parte del equipo del proyecto de investigación "Europeísmo y redes transatlánticas en los siglos XX y XXI” (PGC2018-095884-B-C22), del Ministerio de Ciencia e Innovación del Gobierno de España. Ambos autores pertenecen al Grupo de Investigación Emergente en el Corto Siglo XX Español: Transferencia Político-Social, Cultural y Económica en una Perspectiva Global, de la Universidad Rey Juan Carlos.

\section{Financiamiento}

Los autores no declaran fuente de financiamiento para la realización de este artículo.

\section{Sobre los autores}

Sara Núñez de Prado Clavell es doctora en ciencias de la información, licenciada en geografía e historia y en derecho. Profesora titular y directora del Departamento de 
Humanidades de la Universidad Rey Juan Carlos. Sus investigaciones se centran en la Unión Europea, Turquía y el narcotráfico, y en la Guerra Civil española y el franquismo. https://orcid.org/0000-0002-4809-5892 - Contacto: sara.clavell@urjc.es

Javier Rodríguez Abengózar es máster en relaciones internacionales con Iberoamérica, graduado en historia y periodismo. Es profesor del Área de Historia Contemporánea de la Universidad Rey Juan Carlos. Sus investigaciones se centran en la Guerra Civil española y en la historia del mundo actual.

$$
\text { https://orcid.org/0000-0003-0079-0551 - Contacto: javier.abengozar@urjc.es }
$$

\section{Referencias}

Agencia de la Unión Europea para la Cooperación Policial (Europol). (s. f.). EU Policy Cycle. EMPACT. https://www.europol.europa.eu/empact

Agencia de la Unión Europea para la Cooperación Policial (Europol). (2017) Serious and Organised Crime Threat Assessment, 2017. https://www.europol.europa.eu/socta/2017/

Agencia de la Unión Europea para la Cooperación Policial (Europol). (2021). Serious and Organised Crime Threat Assessment, 2021. https://bit.ly/3ekPC2t

Allum, F., \& Gilmour, S. (2012). Introduction. En F. Allum \& S. Gilmour (Eds.), Routledge handbook on transnational organized crime. Routledge.

Bagley, B. (2014). Narcotráfico y crimen organizado en las Américas: principales tendencias en el siglo XXI. En G. Maihold \& S. Jost (Eds.), El narcotráfico y su combate. Sus efectos sobre las relaciones internacionales (pp. 21-36). Konrad Adenauer Stiftung; Cátedra Guillermo y Alejandro de Humboldt; Edimpro.

Bewley-Taylor, D., \& Jelsma, M. (2016). UNGASS 2016: ¿Un consenso roto o amplio? La cumbre de la ONU no puede ocultar una creciente divergencia en el panorama mundial de las politicas de drogas. Trasnational Institute; Global Drug Policy Observatory.

Convención Única de 1961 sobre Estupefacientes, enmendada por el Protocolo que modifica la Convención única de 1961 sobre estupefacientes. Nueva York, 8 de agosto de 1975. (1981). Boletín Oficial del Estado, 264. https://bit.ly/3qjjzp7

Fundación Internacional y para Iberoamérica de Administración y Políticas Públicas (FIAPP). (2019, 25 de julio). El blanqueo de capitales, una amenaza para la estabilidad social y financiera. https://bit. ly/3qERUPV

Jelsma, M. (2003). Las drogas en el sistema de la ONU: la historia no escrita de la Sesión Especial de la Asamblea General de Naciones Unidas (UNGASS) sobre el problema mundial de las drogas. The Transnational Institute.

Lampe, K. (2001). Not a process of enlightenment: The conceptual history of organized crime in Germany and the United States of America. En P. Arlacchi (Ed.), Forum on Crime and Society (vol. 1, n. ${ }^{\circ} 2$, pp. 99-116). Centre for International Crime Prevention.

Oficina de las Naciones Unidas contra la Droga y el Delito (UNODC). (s. f.). Oficina de las Naciones Unidas contra la Droga y el Delito (UNODC) [página web]. https://www.unov.org/unov/es/unodc.html

Oficina de las Naciones Unidas contra la Droga y el Delito (UNODC). (1988). Convención de las Naciones Unidas contra el Tráfico Ilícito de Estupefacientes y Sustancias Sicotrópicas. https://www.unodc.org/ pdf/convention_1988_es.pdf

Oficina de las Naciones Unidas contra la Droga y el Delito (UNODC). (2004a). Convención de las Naciones Unidas contra la Delincuencia Organizada Transnacional y sus protocolos. https://bit.ly/3FtIf4S 
Oficina de las Naciones Unidas contra la Droga y el Delito (UNODC). (2004b). Informe mundial sobre las drogas. Volumen 1: Análisis. https://bit.ly/3pqdM22

Oficina de las Naciones Unidas contra la Droga y el Delito (UNODC). (2014). Los tratados de fiscalización internacional de drogas. https://bit.ly/3pnWhiH

Oficina de las Naciones Unidas contra la Droga y el Delito (UNODC). (2016). Documento final del periodo extraordinario de sesiones de la Asamblea General de las Naciones Unidas sobre el problema mundial de las drogas celebrado en 2016. https://bit.ly/3Frkydm

Oficina de las Naciones Unidas contra la Droga y el Delito (UNODC). (2019, 22 de marzo). CND2019: Participación récord y alto compromiso de los gobiernos para forjar un camino común frente a los desafíos globales de las drogas. https://bit.ly/3ej6AhN

Oficina de las Naciones Unidas contra la Droga y el Delito (UNODC). (2020, 26 de junio). Informe Mundial sobre las Drogas 2020 de la UNODC: el consumo global aumenta a pesar de que el COVID-19 tiene un impacto de gran alcance en los mercados mundiales de drogas. https://bit.ly/3FqRuCK

Organización de las Naciones Unidas (ONU). (1971). Convenio sobre Sustancias Sicotrópicas de 1971. https://www.unodc.org/pdf/convention_1971_es.pdf.

Organización de las Naciones Unidas (ONU). (2020). Resolución 9/1. Establecimiento del mecanismo de examen de la aplicación de la Convención de las Naciones Unidas contra la Delincuencia Organizada Transnacional y sus protocolos. https://bit.ly/3H8tbtB

Paoli, L. (2002). The paradoxes of organized crime. Crime, Law \& Social Change, 37, 51-97. https://bit. ly/3mvoVwu

Parlamento Europeo \& Consejo de la Unión Europea. (2014, 11 de marzo). Reglamento (UE) 230/2014. Por el que se establece un instrumento en pro de la estabilidad y la paz. Diario Oficial de la Unión Europea L77. https://bit.ly/32wcUQ6

Participación Ciudadana (s. f.). Proyecto Crimjust [página web]. https://pciudadana.org/crimjust/

Programa de los Flujos Ilícitos Globales (PFIG) de la Unión Europea. (s. f.). ¿Qué es el Programa de los Flujos Ilícitos Globales? [página web]. https://illicitflows.eu/es/programa/

Saldarkhan, L. (2020). Los cambios recientes en las rutas del tráfico de cocaina (OCCO Análisis). Observatorio Colombiano de Crimen Organizado, Universidad del Rosario. https://bit.ly/3yUSnkp

Seelke, C., Wyler, L., Beittel, J., \& Sullivan, M. (2011). Latin America and the Caribbean: Illicit drug trafficking and U.S. counterdrug programs [informe]. Congressional Research Services. https://sgp. fas.org/crs/row/R41215.pdf 